\title{
Prevalencia y presencia de factores de riesgo de leptospirosis en una población de riesgo de la Región Metropolitana
}

\author{
Cecilia Perret $\mathbf{P}^{\mathbf{1}}$, Katia Abarca $\mathbf{V}^{\mathbf{1}}$, Jeannette Dabanch $\mathbf{P}^{\mathbf{1}}$, \\ Verónica Solari G ${ }^{1,2, a}$ Patricia García $C^{3}$, Soledad Carrasco L ${ }^{4}$, \\ Roberto Olivares $C^{1}$, Patricia Avalos ${ }^{5, a}$. \\ Risk factors and frequency of positive \\ antibodies for leptospirosis in a sub \\ urban population near Santiago
}

Background: Leptospirosis is a zoonotic disease and its incidence is known in Chile since 2002, when it was incorporated as a disease that must be reported to health authorities. A serologic survey for leptospirosis was performed in humans and animals from a farm in a semi urban area in Santiago Chile, after the death of a farmer due to Weil disease in that place. Aim: To report the prevalence of antibodies against leptospirosis and to determine exposure to infection risk factors in the humans and domestic animals studied in this survey. Material and methods: Antibodies were detected by IgM immunodot and indirect haemagglutination test in 61 humans (43 male, aged 5 to 70 years) and by microscopic agglutination test (MAT) in 44 animals. A questionnaire was applied to determine their exposure to risk factors for infection with Leptospira. Results: Seventy two percent of the studied population were farm workers and $70 \%$ had activities that required contact with water from canals, $41 \%$ cleaned closed places where rodents were present. Other risk factors detected were lack of sewage and waste disposal, high level of rodent infestation and disposal of faeces into canals used for watering. Two humans (3.3\%) and six animals ( 1 bovine and 5 rodents) had positive antibodies. Among animals, antibodies against Leptospira serovar pomona and icterohaemorragiae were detected. Conclusions: In Chile, leptospirosis exists not only in rural areas but semi urban ones close to Santiago, although the prevalence is low. Education is necessary among semi urban population to avoid infection (Rev Méd Chile 2005; 133: 426-31). (Key Words: Leptospirosis; Leptospira interrogans; Weil disease)

Recibido el 17 de agosto, 2004. Aceptado en versión corregida el 6 de enero, 2005.

${ }^{1}$ Comité de Infecciones Emergentes, Sociedad Chilena de Infectología. ${ }^{2}$ SESMA. Unidad de Epidemiología, ${ }^{3}$ Laboratorio Microbiología, Pontificia Universidad Católica de Chile. ${ }^{4}$ Servicio de Salud Metropolitano Central, Unidad de Epidemiología, ${ }^{5}$ Laboratorio y Estación Cuarentenaria y Pecuaria, Servicio Agrícola y Ganadero. Santiago de Chile.

aMédico veterinario

Correspondencia a: Dra. Cecilia Perret P. Departamento de Pediatría, Pontificia Universidad Católica de Chile. Comité de Infecciones Emergentes, Sociedad Chilena de Infectología. Marcoleta 391, 4ํㅜ piso. Fono: 6866825. Fax: 6387457. E mail: cperret@med.puc.cl 
L a leptospirosis es una zoonosis presente en nuestro país, cuya incidencia se conoce a partir del año 2000, cuando fue incorporada como enfermedad de notificación obligatoria a través de vigilancia de laboratorio. En el año 2002 es enfermedad de notificación obligatoria caso a caso $^{1}$, registrándose ese año 22 casos con una tasa de 0,14/100.000 hab, en su mayoría hombres relacionados con actividades laborales de riesgo ${ }^{2}$. En 2003 se notificaron 33 casos, concentrados en los Servicios de Salud de Ñuble y Maule, con una tasa de 0,2/100.000 hab ${ }^{3}$. En el mundo se ha descrito una incidencia de 0,1-1/100.000 en países con clima templado y 10-100/100.000 hab en países tropicales 4 . La seroprevalencia en algunas zonas de riesgo en Chile ha sido de $22 \%$, como en Valdivia ${ }^{5}$.

$\mathrm{El}$ agente causal es una espiroqueta del género Leptospira, especie interrogans, la cual tiene distintos serogrupos y serovares. Leptospira infecta a mamíferos produciendo desde infecciones asintomáticas hasta enfermedad grave. Los roedores sólo presentan infección asintomática. El hombre y otros mamíferos que enferman son considerados hospederos terminales y no representan riesgos de transmisión ya que tienen un corto período de excreción renal de Leptospira. Por el contrario, los animales infectados, que no desarrollan enfermedad, pueden excretar Leptospira a través de la orina por tiempo prolongado, generalmente durante toda su vida ${ }^{4}$. Estos constituyen la principal fuente de transmisión al contaminar el ambiente, especialmente aguas de regadío, fuente de infección más frecuente al hombre. En ocasiones, otros productos o tejidos derivados de estos animales pueden ocasionar la infección al hombre por el contacto directo con piel o mucosas. El reservorio de Leptospira en sectores rurales lo constituyen los bovinos, porcinos, equinos y roedores silvestres. En las zonas urbanas, éste está constituido principalmente por roedores ${ }^{6-8}$ y probablemente perros. Se le considera una enfermedad ocupacional, ya que se presenta principalmente en personas relacionadas con actividades agrícolas, veterinarios, limpiadores de alcantarillados, trabajadores de mataderos y desratizadores ${ }^{1}$. Sin embargo, también se ha asociado a actividades recreacionales, como la inmersión en aguas de regadíos. Un ejemplo de este mecanismo es el brote que afectó a 84 personas de Linares, VII región, que enfermaron al bañarse en una piscina con agua de canales de regadío ${ }^{1}$.

El diagnóstico de leptospirosis se basa fundamentalmente en la sospecha clínica y en la detección de anticuerpos séricos. Los métodos de cultivo, si bien son confirmatorios, son de alta complejidad, baja sensibilidad (45\%) y demorosos, por lo que no son de gran utilidad clínica ${ }^{9}$. Las técnicas de biología molecular como PCR no están disponibles ampliamente.

La determinación de anticuerpos es la forma más utilizada para el diagnóstico de esta enfermedad. La determinación de IgM por ELISA o por test rápidos inmunocromatográficos permite diagnosticar infección aguda. Diversos estudios han mostrado sensibilidad variable entre 36 y $100 \%$ para ELISA y entre 52 y 94\% para los métodos inmunocromatográficos $^{10-17}$ que son más sencillos, rápidos y no requieren equipamiento.

La técnica de hemaglutinación indirecta (HAI) determina anticuerpos totales (IgM e IgG) por lo que no permite diferenciar infección reciente de pasada. Es útil para estudios de seroprevalencia y es la recomendada por el Centro de Control de Enfermedades en Atlanta para su uso en laboratorios clínicos, ya que presenta una sensibilidad de $92 \%$ y una especificidad de $97 \%$ respecto del $\mathrm{MAT}^{18}$.

El test de aglutinación microscópica (MAT) es considerado el método serológico definitivo por su alta especificidad y porque diagnostica el serovar infectante. Determina anticuerpos totales (IgM e IgG), mediante aglutinación con antígenos de distintos serovares de Leptospira, por lo que una muestra de suero aislada no permite hacer el diagnóstico de infección aguda. Se requiere seroconversión o aumento de títulos en dos muestras de suero consecutivas. Existe reacción cruzada entre los anticuerpos de los distintos serovares, especialmente al comienzo de la infección. Es técnicamente complejo y requiere de personal entrenado para su interpretación. Por estas razones se reserva para laboratorios de referencia. La sensibilidad del MAT es variable, dependiendo del número de serovares incluidos en el panel. Un resultado puede ser falsamente negativo si el serovar infectante no se encuentra dentro de los antígenos utilizados para la prueba ${ }^{9}$.

A pesar de la disponibilidad de estas técnicas, el diagnóstico de leptospirosis aún plantea dificulta- 
des. Los anticuerpos tipo IgM aparecen luego de 510 días de iniciada la sintomatología y pueden durar elevados por varios meses o años. De esta forma, muestras analizadas precozmente pueden ser falsamente negativas y muestras tardías pueden ser falsamente positivas de enfermedad aguda. La seroconversión o el incremento de títulos de anticuerpos, en al menos cuatro veces entre dos muestras, se considera confirmatorio de infección aguda por Leptospira. Basado en todas estas consideraciones, el resultado serológico de una muestra aislada, debe ser analizado en conjunto con el cuadro clínico y los antecedentes epidemiológicos de exposición para su adecuada interpretación.

En el verano de 2002, se diagnosticaron en la Región Metropolitana 3 casos de leptospirosis. Uno de ellos correspondió a un trabajador de un fundo aledaño a Santiago, quien falleció luego de presentar la forma grave de leptospirosis (enfermedad de Weil). El diagnóstico fue mediante ELISA IgM y MAT, la cual demostró anticuerpos anti-L canícola en títulos 1:102.400 y anti-Licterohaemorrhagica en títulos de 1:3.200.

Este paciente motivó el presente estudio, cuyos objetivos fueron determinar la frecuencia de anticuerpos anti-Leptospira en humanos expuestos a riesgo ocupacional o residencial y la seroprevalencia en los animales domésticos y silvestres de esa zona. También evaluar la presencia de factores de riesgo ambientales o conductuales conocidos para la infección por Leptospira con el fin de realizar actividades destinadas a la prevención de esta enfermedad.

\section{Metodología}

Se realizó un estudio descriptivo y colaborativo de varias instituciones consistente en una visita epidemiológica al fundo donde vivía el caso índice, para evaluar la situación ambiental y hábitos de la población tales como: actividades con agua de regadío, disposición de excretas, eliminación de basura y limpieza de sitios cerrados. También se midió mediante un instrumento del SESMA el riesgo de infestación murina. Se enrolaron personas que residían o trabajaban en este fundo y que aceptaron participar, previa firma de consentimiento informado. Se aplicó una encuesta especialmente diseñada registrándose datos demográficos, laborales, exposi- ción a distintos riesgos y síntomas sugerentes de leptospirosis. Además, se les tomó una muestra de 5 $\mathrm{ml}$ de sangre venosa para la determinación de anticuerpos séricos anti-Leptospira mediante las técnicas de IgM por inmunocromatografía y HAI realizados en el Laboratorio de Microbiología de la Pontificia Universidad Católica de Chile. A aquellos que resultaron positivos por estas técnicas se les realizó MAT en el laboratorio del SAG.

Se tomaron muestras de sangre a algunos de los animales del fundo: bovinos, porcinos, ovinos y roedores para la identificación de anticuerpos anti-Leptospira mediante la técnica de MAT.

La determinación de IgM mediante inmunocromatografía (LeptoTek Lateral Flow ${ }^{\circledR}$, BioMerieux, Mo) consiste en un inmunoensayo de reacción antígeno anticuerpo donde un antígeno de Leptospira es inmovilizado sobre una membrana de nitrocelulosa. Sobre esta membrana se aplica el suero del paciente, que si contiene IgM antiLeptospira se formará un complejo antígeno anticuerpo el cual es revelado por la aparición de una línea al agregar un anticuerpo anti-IgM humana marcada con partículas de oro rojo coloidal.

La hemaglutinación indirecta (MRL Diagnostics $^{\circledR}$, Ca) utiliza eritrocitos sensibilizados con antígeno derivado de Leptospira biflexa cepa Patoc 1. Cuando existen anticuerpos en el suero del paciente (IgG o IgM) ocurre una aglutinación de los glóbulos rojos. Utiliza eritrocitos no sensibilizados como control para evaluar reacciones inespecíficas. Se comienza con una dilución inicial 1:50 y, de ser positivo, se realizan diluciones seriadas hasta determinar la dilución límite de positividad.

La microaglutinación (MAT) consiste en la mezcla de diluciones seriadas del suero del paciente con cultivos de Leptospira de distintos serovares en placas de microtitulación o en tubos. Las mezclas de suero con los antígenos de Leptospira se dejan reaccionar por 2 a $4 \mathrm{~h}$ a $30^{\circ} \mathrm{C}$. El grado de aglutinación y el título final se determina examinando cada mezcla por microscopia de campo oscuro.

\section{Resultados}

Se encuestaron, de un total de 149 residentes y trabajadores, 61 personas (41\%) distribuidos ho- 
mogéneamente dentro del fundo. De los encuestados, 43 personas (70\%) eran de sexo masculino. La mediana de edad fue 37 años (5-70), siendo $75 \%$ menores de 50 años. Sesenta y dos porciento de la población tenía algún grado de educación básica. En la población estudiada se encontró la presencia de distintos factores de riesgo, como el ser residente del fundo, desarrollar labores agrícolas, contacto con agua de acequias, limpieza de lugares cerrados donde se había detectado la presencia de roedores y falta de protección personal en labores de alto riesgo, como el uso de botas de goma para actividades de regadío. La frecuencia de estos factores se resume en la Tabla 1.

Se encontraron 2 personas $(3,3 \%)$ con anticuerpos positivos anti-Leptospira mediante HAI;
Tabla 1. Frecuencia de factores de riesgo asociados a leptospirosis en 61personas encuestadas en el fundo

\begin{tabular}{|lcc|}
\hline Factor de riesgo & $\mathrm{n}$ & $(\%)$ \\
\hline Residentes del fundo & $41 / 61$ & $(67)$ \\
Labores agrícolas & $44 / 61$ & $(72)$ \\
Contacto agua de acequia & $43 / 61$ & $(70)$ \\
Limpieza de sitios con & $25 / 61$ & $(41)$ \\
infestación murina & & \\
$\begin{array}{l}\text { Uso inadecuado de equipo } \\
\text { de protección personal }\end{array}$ & $24 / 24$ & $(100)$ \\
$\begin{array}{l}\text { Viviendas sin } \\
\text { alcantarillado }\end{array}$ & $33 / 33$ & $(100)$ \\
\hline
\end{tabular}

Tabla 2. Presencia de anticuerpos anti-L eptospira en animales del fundo estudiados mediante técnica de M AT en el SAG

\begin{tabular}{|lccc|}
\hline Especie & № estudiados & № positivos & Serovar \\
\hline Bovinos & 3 & 1 & L pomona \\
Porcinos & 4 & 0 & - \\
Ovinos & 2 & 0 & - \\
Roedores & 35 & 5 & Licterohemorrágica \\
& & $(14 \%)$ & \\
\hline
\end{tabular}

un niño de 7 años, nieto del caso índice y un adulto de 64 años, ambos residentes del fundo. En ambos casos la IgM y MAT fueron negativas.

Se estudiaron por MAT 44 animales; 4 porcinos, 3 bovinos, 2 ovinos y 35 roedores, resultando positivos 6 de ellos con una prevalencia de 14\%. Los animales positivos fueron un bovino con anticuerpos anti-Leptospira pomona en títulos 1:200 y 5 roedores con anticuerpos anti-Licterohemorrágica (Tabla 2). Tanto roedores silvestres como urbanos fueron positivos para infección por Leptospira (Tabla 3). Los perros del lugar no fueron estudiados, pues fueron vacunados contra leptospirosis durante la primera visita del equipo de salud ambiental, como medida de control de un posible brote.

El estudio ambiental reveló que la totalidad de las viviendas (33) de los encuestados eran de madera, con agua potable disponible en llave en el patio y que no contaban con sistema de alcantarillado. Las aguas servidas eran vaciadas al canal y la disposición de basuras era a canales y sitios aledaños. El puntaje obtenido por el instrumento del SESMA, que determina riesgo de roedores, fue de $32 / 42$, clasificando al lugar como de alto riesgo de infestación murina.

Conocidos los resultados del estudio ambiental y conductual, se realizaron algunas intervenciones

Tabla 3. D escripción de los roedores del fundo EI Bosque y su frecuencia de anticuerpos anti-Leptospira estudiados mediante técnica de MAT en el SAG

\begin{tabular}{|lcc|}
\hline Especie & № estudiados & № positivos (\%) \\
\hline Mus musculus & 13 & $0(0 \%)$ \\
Abrothrix olivaceus & 10 & $1(10 \%)$ \\
Rattus norvegicus & 9 & $3(33 \%)$ \\
Rattus rattus & 3 & $1(33 \%)$ \\
Total & 35 & $5(14 \%)$ \\
\hline
\end{tabular}


por el equipo de higiene ambiental de la Municipalidad de Maipú y del SESMA, como vacunación a los caninos del fundo, desratización del predio y actividades educativas a la población tendientes a disminuir las actividades riesgosas y controlar la proliferación de roedores.

\section{DisCUSIÓN}

Este estudio demuestra que la infección por leptospirosis existe en Chile, no sólo en zonas rurales sino que también en zonas periurbanas cercanas a Santiago, aunque ligadas a actividades agrícolas. La población de este fundo fue considerada de riesgo al existir el antecedente de un paciente que falleció por la forma grave de leptospirosis. Esto hizo sospechar que los trabajadores y habitantes del lugar podrían estar expuestos a las mismas fuentes infectantes que el caso índice. A pesar de esta hipótesis, y de haber constatado la presencia de varios de los factores de riesgo conocidos para leptospirosis, sólo 3,3\% de las personas estudiadas reveló haber tenido infección por Leptospira. No se ha descrito la transmisión persona-persona en leptospirosis, por lo que el hallazgo de personas infectadas en el mismo fundo sugiere la exposición a los mismos factores ambientales. La prevalencia de leptospirosis de esta población es baja en comparación con otras poblaciones de riesgo estudiadas en Chile (trabajadores agrícolas, trabajadores de mataderos), en que se encontró $22 \%$ de la población con anticuerpos anti-Leptospira ${ }^{5}$. Estas cifras, probablemente, reflejan diferencias en la distribución geográfica de riesgo de adquirir leptospirosis a lo largo de Chile y en el tipo de poblaciones expuestas en relación con las actividades que realizan. El estudio que demuestra mayor prevalencia incluye, además de una población de trabajadores agrícolas, una población de trabajadores de mataderos, por lo que no es posible compararla con la población incluida en nuestro estudio. La selección de nuestra muestra no fue al azar sino que incluyó a quienes estaban interesados en participar. Puede haber aquí un sesgo de selección y la muestra no ser representativa de la población expuesta al riesgo real. Parece menos probable explicar la baja seroprevalencia por una baja sensibilidad de los métodos de diagnóstico utilizados, ya que como se comentó, la sensibilidad de la HAI respecto de MAT es alta (varía entre 81 y 92\%) para diagnóstico de leptospirosis aguda $\mathrm{y}$ puede llegar a $100 \%$ con una segunda muestra, después de la primera semana del inicio de los síntomas ${ }^{12,18}$. En un trabajo realizado por uno de los autores, se evaluó la sensibilidad y especificidad de la HAI y de un método inmunocromatográfico en 40 pacientes con sospecha de leptospirosis aguda encontrándose para ambas técnicas una sensibilidad de $86 \%$ y una especificidad de $100 \% 19$.

Destaca que las dos personas con serología positiva mediante HAI no lo fueron por el método MAT. Esta falta de correlación puede deberse a que el análisis de los sueros por los distintos métodos no fue contemporáneo, por lo que alteraciones en la calidad de ellos, luego de la manipulación, pudo haber afectado el resultado final. No se logró, por lo tanto, determinar el serovar de Leptospira en las dos personas que resultaron positivas. La posibilidad de falsos positivos por la técnica HAI parece menos probable considerando la buena especificidad del método. $\mathrm{Si}$ bien se han descrito falsos positivos en pacientes con dengue, hepatitis $\mathrm{A}$, fiebre $\mathrm{Q}$, enfermedad de Lyme y sífilis, no parece ser el caso de estas dos personas.

En el caso particular de este fundo, el factor de riesgo más importante de adquirir leptospirosis es probablemente la alta infestación de roedores, asociado a las malas condiciones ambientales de vivienda como disposición de excretas y basura que favorecen la proliferación de éstos. El hallazgo de anticuerpos positivos en $14 \%$ de los roedores capturados anti-L icterohemorragiae, uno de los serovares encontrados en el caso índice y que se asocia a evolución grave de la enfermedad, apoya la idea que los roedores sean un reservorio importante de Leptospira. Estos cumplirían un rol significativo en la transmisión de esta infección en esta población en particular y en zonas urbanas y periurbanas en general. En estos lugares, los perros también son considerados fuente importante de infección, sin embargo esta afirmación no pudo ser comprobada en este predio ya que los perros fueron precozmente vacunados antes de la realización del estudio serológico.

Finalmente, podemos concluir que, dado la confirmación de animales infectados por Leptospira $\mathrm{y}$ la presencia de factores de riesgo en zonas agrícolas periurbanas de Santiago, debe considerar- 
se el diagnóstico de leptospirosis en sujetos con síntomas compatibles que vivan o trabajen, no sólo en zonas rurales, sino también periurbanas. Se hace necesario la implementación de actividades educativas en estas comunidades destinadas a prevenir

\section{REFERENCIAS}

1. Navarrete G. Vigilancia de leptospirosis. Departamento de Epidemiología. MINSAL Circular № 4F/03, 2002.

2. SотомауоR V. ENO. Zoonosis y Chagas. El Vigia, Boletín de vigilancia en Salud Pública de Chile. 2002; 6 (17): 28.

3. Situación de las enfermedades de notificación obligatoria. Antrax, Brucelosis, Triquinosis, Leptospirosis, Hidatidosis y Enfermedad de Chagas e-vigía. Boletín electrónico mensual de vigilancia epidemiológica. 2004; 24. http://epi.minsal.cl/ evigia/index.htm

4. WHO, International Leptospirosis Society. Human leptospirosis: Guidance for diagnosis, surveillance and control 2003. 114 páginas ISBN: 924 1545895.

5. Zamora J, Riedemann S. Encuesta serológica de leptospirosis humana en ocupaciones de alto riesgo en Chile. Rev Méd Chile 1990; 118: 247-52.

6. Riedemann S, Zamora J. Leptospirosis ¿Zoonosis sin trascendencia en Chile? Rev Méd Chile 1998; 116: 1066-9.

7. RiedemanN S, Zamora J. Leptospirosis en roedores silvestres capturados en la ciudad de Valdivia. Diagnóstico por serología y tinción inmunoquímica. Agrociencia 1994; 10: 133-8.

8. Zunino E, Palomino C. Leptospirosis. Análisis de 36 casos, 1983-1984. Rev Chil Infect 1985; 2: 110-16.

9. Levett P. Leptospirosis. Clin Microbiol Rev 2001; 14: 296-326.

10. Gussenhoven GC, Van Der Hoorn MAWG, Goris MGA, TeRPSTRA WJ, HaRTSKeERL RA, Mol BW et al. LEPTO Dipstick. A Dipstick Assay for Detection of Leptospira Specific Immunoglobulin M Antibodies in Human Sera. J Clin Microbiol 1997; 35: 92-7.

11. Winslow WE, MerRy DJ, PirC ML, Devine PL. Evaluation of a Commercial Enzyme-Linked Imnunosorbent Assay for Detection of Immunoglo- en forma eficiente la infección. Son necesarios más estudios para tener información más precisa de la distribución geográfica y actividades de mayor riesgo de leptospirosis a lo largo de Chile.

bulin M Antibody in Diagnosis of Human Leptospiral Infection. J Clin Microbiol 1997; 35: 1938-42.

12. Leveit PN, WhitTington CU. Evaluation of the Indirect Hemmagglutination Assay for Diagnosis of Acute Leptospirosis. J Clin Microbiol 1998; 36: 11-4.

13. Smits HL, Ananyina YV, Chereshsky A, Dancel L, LaIA-FAt RFM, CheE HD ET AL. International Multicenter Evaluation of the Clinical Utility of a Dipstick Assay for Detection of Leptospira-Specific Immunoglobulin M Antibodies in Human Serum Specimens J Clin Microbiol 1999; 37: 2904-9.

14. Flannery B, Costa D, Pinheiro Carvalho F, Guerreiro $\mathrm{H}$, Matsunaga J, Domingos Da Silva E et al. Evaluation of Recombinant Leptospira AntigenBased Enzyme-Linked Imnunosorbent Assays for the Serodiagnosis of Leptospirosis. J Clin Microbiol 2001; 39: 3303-10.

15. EFFier PV, Bogard AK, Domen HY, Katz AR, Higa HY, SASAKI DM. Evaluation of Eight Rapid Screening Tests for Acute Leptospirosis in Hawaii. J Clin Microbiol 2002; 40: 1464-9.

16. Eapen CK, Sugathan S, Kuriakose M, Abdoel T, Smits HL. Evaluation of the clinical utility of a rapid blood test for human leptospirosis. Diagnostic Microbiology and Infectious Disease 2002; 42: 221-5.

17. Bajani MD, Ashford DA, Bragg SL, Woods CW, Aye T, Spiegel RA et al. Evaluation of Four Commercially Available Rapid Serologic Tests for Diagnosis of Leptospirosis. J Clin Microbiol 2003; 41: 803-9.

18. Sulzer CR, Glosser JW, Rogers F, Jones WL, Frix M. Evaluation of an Indirect Hemmaglutination Test for the Diagnosis of Human Leptospirosis. J Clin Microbiol 1975; 2: 218-21.

19. García P, Triantafilo V, Guzmán AM, Braun $\mathrm{S}$, Morales R, URRa L et aL. Leptospirosis aguda: Evaluación de tres métodos de diagnóstico serológico. XIX Congreso Chileno de Infectología. Santiago, 2002. 